\title{
Fósseis do Campo Psi: sobre Conversão de Orientação Sexual e Gênero
}

\author{
Gabriel Binkowski ${ }^{1}$ \\ ${ }^{1}$ Universidade de São Paulo, SP, Brasil.
}

\begin{abstract}
Resumo: Neste escrito analisamos a atualidade das discussões sociais e políticas em torno das práticas de conversão de orientação sexual e de gênero. Propomos pensar os riscos que teorias e técnicas estruturantes do campo psi - Psicanálise, Psicologia e Psiquiatria - têm de serem capturadas por grupos sociais, políticos e religiosos que podem utilizá-las para legitimar e ampliar o poder e o alcance de suas proposições no tocante ao exercício da sexualidade e à identidade de gênero. Construímos a hipótese de que certos fósseis morais, religiosos e conceituais, que pertencem aos registros lógicos e históricos das teorias e discursividades constituintes do campo psi, acabam sendo registros privilegiados para tal captura de práticas e de sentido conceitual. Dentre estes fósseis, citamos as discussões sobre a natureza psicopatológica da homossexualidade e mesmo sobre a formação de psicanalistas homossexuais, o que provocou debates intensos até tempos bastante recentes.
\end{abstract}

Palavras-chave: Cura Gay, Conversão Sexual, Psicanálise, Homossexualidade, Religião.

\section{Psy Fossils: On Sexual Orientation Conversion and Gender}

\begin{abstract}
In this paper we analyze the current social and political discussions around the practices of conversion of sexual orientation and gender. We propose to think about the risks that the theories and structuring techniques of the field of psychoanalysis, psychology and psychiatry involve if captured by social, political and religious groups that can use them to legitimize and broaden the power and scope of their propositions regarding exercise of sexuality and gender identity. We construct the hypothesis that certain moral, religious, and conceptual fossils, which belong to the logical and historical records of the constituent theories and discursivities of the psy field, end up being privileged records for such capture of practices and conceptual sense. Among these fossils, we cite the discussions about the psychopathological nature of homosexuality and even about the formation of homosexual psychoanalysts, which provoked intense debates until quite recent times.
\end{abstract}

Keywords: Gay Cure, Sexual Conversion, Psychoanalysis, Homosexuality, Religion. 


\title{
Fósiles del Campo Psi: sobre Conversión de la Orientación Sexual y del Género
}

\begin{abstract}
Resumen: En este artículo analizamos las discusiones sociales y políticas actuales sobre las prácticas de conversión de orientación sexual y de género. Proponemos pensar en los riesgos que tienen que capturar las teorías y técnicas de estructuración en el campo psi - psicoanálisis, psicología y psiquiatría por parte de grupos sociales, políticos y religiosos que pueden usarlas para legitimar y extender el poder y el alcance de sus proposiciones con respecto al ejercicio de sexualidad e identidad de género. Presumimos que ciertos fósiles morales, religiosos y conceptuales, que pertenecen a los registros lógicos e históricos de las teorías y discursividades que constituyen el campo psi, terminan siendo registros privilegiados para tal captura de prácticas y de significado conceptual. Entre estos fósiles, citamos discusiones sobre la naturaleza psicopatológica de la homosexualidad e incluso sobre la formación de psicoanalistas homosexuales, lo que ha provocado un intenso debate hasta tiempos muy recientes.
\end{abstract}

Palabras clave: Cura Gay, Conversión Sexual, Psicoanálisis, Homosexualidad, Religión.

\section{A homossexualidade e o campo psi num mundo que se despia da religião}

O conceito de homossexualidade é bastante recente, tendo sido empregado pela primeira vez, por volta de 1860, pelo médico húngaro Karoly Maria Benkert (Roudinesco, \& Plon, 1998). Mais recente ainda é a estabilidade de uma noção de "homossexual" - enquanto permanência de uma orientação de desejo e experiência de uma identidade socialmente partilhável. Algo que se constituiu, ao longo do século XX por meio de uma mobilização social, política, intelectual e cultural (Coulmont, 2010). Chama a atenção, nesse ínterim, a ambiguidade das ciências ditas psicológicas na relação com essa discursividade. Com efeito, ao longo desse século em que conceitos derivados da Psiquiatria, da Psicologia e da Psicanálise foram se imbricando na cultura e fazendo parte da armadura semântica com a qual os humanos se narram, a homossexualidade passou de inversão sexual, anomalia psíquica e distúrbio de identidade a escolha inconsciente de objeto sexual e/ou determinação comportamental e psicogenética.

Muito embora o paralelo possível entre a laicização das práticas sociais e o desenvolvimento das ciências e tecnologias de gestão de populações seja evidente a partir da modernidade, a homossexualidade foi, por muito tempo, encarada enquanto um comportamento desviante, uma prática ou conjunto de práticas corporais em que $\mathrm{o}$ ato sexual não compreendia a cópula genital com um parceiro do sexo oposto.
Ora, a história da patologização da homossexualidade (e não apenas de comportamentos homossexuais) anda como carruagem alada com o desenvolvimento das ciências psi e com a ampliação do poder da autoridade psiquiátrica perante as sociedades ocidentais no século XX.

Ademais, evidencia-se que a ampliação da autoridade das ciências psi dizia respeito a um deslocamento do registro mesmo da autoridade ao longo do século passado, tendo em vista que os saberes e práticas das ciências aplicadas passaram a operar como lócus de depósito de certas regras, normas e de implícitos que deveriam dar nexo a políticas públicas, à gestão política e ao próprio espaço de negociação que chamamos de moralidade. De tal deslocamento, no registro de autoridade, partiu precisamente a passagem de uma cosmologia mítico-religiosa para outra cujo arcabouço seria composto pelo próprio campo semântico das ciências. Como num enredo operístico, portanto com seu dégradé de tragicidade, essa passagem fora hipotetizada por Freud no livro Futuro de uma ilusão (1927/2011). Ali encontramos a constatação de que as explicações e ideologias místicas e religiosas, outrora tão necessárias para o tecido social em tempos nos quais o desconhecido e a natureza se equivaliam, poderiam ser suplantadas por outras advindas da ciência e de saberes que dariam ao sócius a possibilidade de livrar-se das sombras do pensamento religioso. $\mathrm{O}$ mundo parecia ir se despindo da religião. Mas a que custos? 


\section{Laicização, secularização e os fósseis morais no caminho dos saberes psi}

A fim de operarmos conceitualmente com o já mencionado espaço discursivo da homossexualidade, é peremptório nomear o fenômeno descrito no parágrafo anterior, diagnosticado inclusive por Freud, a partir do par laicização e secularização. Na perspectiva da laicização, coisa religiosa e coisa política ficam estritamente separadas na construção de aparatos legislativos, jurídicos e governamentais. Assim, a laicização é um instrumento legal de retirada da religião (suas práticas, ideologias e ideário) da coisa política. Já a secularização é um processo no qual uma sociedade vai paulatinamente deixando de lado os ingredientes religiosos naquilo que seria o composto simbólico-imaginário de uma população. Processos em devir e dialéticos, efetivamente, tanto secularização quanto laicização pareciam se retroalimentar ao longo do século passado, dando espaço para que outros conglomerados discursivos fizessem as vezes de fios da tessitura do social.

No entanto, os discursos e saberes que fomentam essa suposta nova ordem política não são operados numa lógica de tábula rasa. Eles herdam disposições morais e uma serialidade lógica (e inconsciente) de campos discursivos que jaziam anteriormente no vespeiro social. No que diz respeito ao campo psi e sua importância como operador no social e na política, é evidente que houve certa continuidade e que os saberes da psicologia, psiquiatria e da psicanálise acabaram por reagir àquilo que lhes era demandado. É inegável que podemos nos deparar com certos fósseis morais e/ ou lógicos que habitam nossas disciplinas de trabalho. Na história da psiquiatria e dos manuais de classificação diagnóstica, por exemplo, já se conhece a história e os efeitos da patologização da homossexualidade. No caso do DSM-I (Manual Diagnóstico e Estatístico de Transtornos Mentais, a primeira edição tendo sido publicada em 1952), a homossexualidade aparecia como "transtorno de personalidade sociopática", enquanto a segunda edição do manual dava destaque para os "desvios sexuais", com o que se diagnosticava indivíduos interessados por atos sexuais ou por coito praticado em condições contrárias à natureza (Lieberman, 2016). Nas alcovas dessa polêmica psiquiátrica, uma das figuras-chave foi Robert Spitzer, que avalizou a partir dos anos 1970 uma discussão a respeito do "distúrbio de orientação sexual" (que ficaria conceitualmente operante especialmente após o DSM-III), segundo o qual o sofrimento subjetivo causado pela experiência do desejo homossexual é levado em conta.

\section{A psicanálise, os homossexuais e sua cura}

Tanto na psiquiatria americana quanto na europeia - e mundo afora -, o tema da reorientação do desejo sexual e da conversão de identidade sexual acabou parasitando os nichos conceituais com os quais composições teóricas do campo psi sustentavam suas práticas. No caso da psicanálise, mesmo Freud já notando relativo acolhimento da "variante da escolha do objeto sexual", o movimento psicanalítico, seguindo a posição de figuras como Ernst Jones, armou barreiras teóricas e técnicas quanto à formação de analistas de orientação homossexual. Sobre as teóricas, isso diria respeito a uma suposta evolução final do desenvolvimento da genitalidade (haja vista que o homossexual se fixaria em etapas de satisfação pulsional anteriores à satisfação genital). Quanto às técnicas, insistia-se na incapacidade de analistas homossexuais operarem enquanto ideal de eu para pacientes, já que eles mesmos não teriam chegado a um nível suficiente de desenvolvimento libidinal por conta das supostas limitações na formação egoica de homossexuais.

No que diz respeito ao tema da "cura da homossexualidade", evoca-se com frequência a carta de resposta de Freud a uma senhora estadunidense, que se apresentou como mãe de um jovem homossexual (sem citar essa palavra), consultando-o sobre as possibilidades terapêuticas da psicanálise para seu filho. Entregue mais tarde anonimamente a Alfred Kinsey (biólogo estadunidense responsável por amplos estudos na área de sexualidade humana), vemos Freud, nessa carta de 1935, manter-se fiel a um espírito psicanalítico em que toda a orientação terapêutica era dada pelo desejo do paciente. Se ele tivesse conflitos psíquicos, inibições sociais e dificuldades com seus desejos sexuais, a psicanálise poderia lhe trazer "paz de espírito"; porém, sentenciava Freud, malgrado todas as perseguições e dificuldades da vida de um homossexual, essa inclinação não seria patológica, e sim uma condição de estabilização e fixação num tipo de objeto de desejo, algo que poderia, ou não, se transformar ao longo de um tratamento (Menahem, 2003).

Ao salientar o caráter da "imprevisibilidade" terapêutica da psicanálise, Freud traçou uma linha estrita da ética da psicanálise: mesmo que algo possa desaparecer na vida de uma pessoa, que possa haver uma transformação psíquica enorme no curso de um trata- 
mento, o farol-guia para uma análise é o do desejo do sujeito. Jacques Lacan, que cita pouquíssimas vezes a palavra homossexual ao longo de sua trajetória, assinala no quinto ano do seu Seminário (1957-1958) uma sentença peremptória sobre as formações do inconsciente: "Quanto aos homossexuais, falamos disso. Os homossexuais, nós os tratamos. Os homossexuais, nós não os curamos. E isso é o que há de mais formidável, que mesmo que se possa curar uma homossexualidade, eles não sejam curáveis" (Lacan, 1998, p. 207, tradução e grifos nossos).

Pois bem, ao nos atermos à sentença de Lacan, tentamos já sinalizar para algo que perpassa a questão da cura homossexual, e que, de alguma forma, atravessa também a escolha de palavras feita pelo autor (curar e curáveis). No original em francês, ele fala em guérir, que designa tanto a cura física e resolutiva do corpo em tratamento, quanto a cura religiosa, a cura milagrosa que vence uma condição tida por incurável. Podemos, ainda, contar com a proximidade entre o substantivo feminino a cura (no sentido analítico) e o substantivo masculino o cura, que é o religioso, o pároco, o vigário de aldeia, aquele que administra almas em alguma comunidade, guiando-as primordialmente pela palavra da moralidade. A cura pela palavra, propriamente dita, foi um tema bastante importante dos anos iniciais da psicanálise, quando do tratamento catártico e hipnótico operou-se uma passagem à cura pela fala.

\section{A cura pela fé: entre resíduo e ameaça}

A discussão entre a proximidade da terapêutica psicanalítica (ou das pré-psicanalíticas, como se costuma dizer) e a cura religiosa foi um tema muito explorado por figuras seminais para a criação do método psicanalítico por Freud. Referimo-nos expressamente a Breuer e Charcot. Breuer, coautor de Estudos sobre a histeria (1895/1971) já escrevia nessa mesma obra, em um capítulo de sua autoria integral, sobre a proximidade de natureza entre as entidades psicopatológicas que podiam ser tratadas com o método catártico e as possessões demoníacas medievais. Ele até conjecturava que todos os antigos fenômenos religiosos poderiam ser considerados manifestações histéricas. Eminente psiquiatra francês e figura-chave e um dos primeiros ideais de Freud, Charcot abordou em sua obra final e testamentária (de publicação póstuma) o tema das curas pela fé, que vinham à época sendo chamadas de faith healing (Charcot, 1892/2015).
Tratava-se das curas obtidas em peregrinações religiosas, dos milagres operados em lugares de adoração (como Lourdes, na França) e em encontros religiosos que aconteciam no velho e no novo mundo. Faz-se necessário mencionar que o movimento protestante evangélico já se desenvolvia com esplendor tanto em áreas urbanas quanto rurais dos Estados Unidos, atraindo multidões para os grandes encontros de predicação e fé, os camp meetings, nos quais massas eram atingidas pelos dons do Espírito Santo e saíam renascidas na fé e, algumas vezes, curadas de enfermidades físicas, doenças psicológicas e maldições espirituais dos mais variados tipos (Fath, 2005; Plunkett, 2009). Entretanto, o que aparece em filigrana no texto de Charcot (1892/2015) é o que mais tarde a sociologia chamaria de retorno do religioso num mundo moderno em franco processo de desencantamento. Essa última expressão, o desencantamento, cara a Weber (1905/1964), servia para falar desse recuo da coisa religiosa para as áreas mais residuais da esfera social, já que a política e a vida em si se organizavam em torno da ciência, da tecnologia, da industrialização e da própria razão. No caso do retorno do religioso, teríamos uma volta do religioso tanto nos espaços da vida privada quanto da vida pública, em seus discursos, suas técnicas, saberes e políticas.

Portanto, ao evocar a cura do corpo pela fé, Charcot acabou por mencionar esse fantasma que sempre espreita as terapêuticas ocidentais, racionais e científicas: o da religião que retorna naqueles espaços residuais entre corpo e mal-estar, entre aquilo que encarna a vontade e certas normas e discursos que vêm ali operar o que poderia ser uma ameaça a determinadas configurações de gozo. É nesse espaço intermediário, como um hímen, que localizamos o que temos chamado de fósseis, esses aparatos lógico-significantes cuja materialidade perpassa tramas culturais e racionalidades do político e da ciência. A psicanálise, por ser um campo e uma prática liminar, litoral, se situa nesse mesmo tipo de materialidade entre zonas de subjetividade e de subjetivação, de sentido e não sentido. Por isso, seu risco de captura e sequestro não pode ser negligenciado.

\section{Ameaças que vêm dos discursos religiosos: confusões de sentido}

As religiões enquanto instâncias organizadas e estruturadas e os discursos religiosos que navegam pelos mais variados bolsões sociais carregam certas 
concepções estruturais de gênero, de performatividade e de regulações para esses elementos (Butler, 2005). Ultimamente, temos testemunhado um "retorno furioso" da religião (expressão do sociólogo Berger) nas mais diversas esferas da vida pública, indo dos espaços político-legislativos à educação e à gestão da saúde. No Brasil, isso se configura de forma um tanto estridente, especialmente por conta dos inúmeros bolsões sociais nos quais reina a desgovernança, particularmente para as populações mais carentes que não encontram apoio do Estado em setores cruciais da vida, como educação, saúde, gestão do espaço urbano, etc. Nesses espaços onde a religião volta a operar com força, tornam-se a codificar as relações intersubjetivas, as técnicas de cuidado e de gestão de populações e a própria semântica das existências (em suas inscrições psíquicas), a partir desses fósseis que habitavam as mais diferentes instâncias do social, incluindo disciplinas e teorias com as quais se operava no campo social.

Um dos casos mais retumbantes dessa espécie de retorno do religioso vem sendo precisamente a tentativa de regulamentar práticas da Psicologia (e mesmo a própria psicanálise enquanto "profissão") de modo a validar e legitimar as tentativas de conversão de gênero ou de identidade sexual. Desde o final dos anos 1990, temos nos deparado com discussões legislativas sobre o devir e a jurisprudência das psicoterapias, num movimento que é transnacional. Roudinesco (2004) reconhece esse movimento como aliado de uma prática de Estado e de governança segundo a qual a compreensão da psique deve trabalhar para manter o sujeito estático, submisso e cronificado, com fluxos e desejos calcados no mercado, algo bastante neoliberal.

No Brasil, o discurso religioso, quando no poder Legislativo por meio de atores eleitos, tem incessantemente agido para legislar questões como a da terapêutica das toxicomanias e para evitar toda discussão que leve em conta as evidentes transformações da sociedade, do tipo de organização familiar, da evolução dos costumes e também da própria presença da ciência na sociedade (desde a temática do aborto na saúde pública ao próprio ensino da teoria darwinista). Desde o início dos anos 2000, tentativas de legislar sobre a prática da Psicologia e das psicoterapias vêm ocorrendo também quanto ao fantasma de cura da homossexualidade e de todas as formas não convencionais de identidade sexual (Natividade, 2006). Em ações que vêm se espraiando desde 2003 - como o Projeto de Lei $n^{\circ} 717 / 2003$, de autoria do deputado religioso Édino Fonseca, da Assembleia Legislativa do Estado do Rio de Janeiro, apoiado por grupos pastorais como o Movimento pela Sexualidade Sadia (Moses) e o Corpo de Psicólogos e Psiquiatras Cristãos (CPPC) -, a tentativa de legislar sobre as práticas psi tem se valido de certos nós teóricos, técnicos e mesmo institucionais que ainda são fósseis no coração das disciplinas psi.

Tais nódulos, esses fósseis, parecem apontar para pontos cegos teóricos ou mesmo para questões que ainda assombram as concepções técnicas e ontológicas das psicoterapias e da psicopatologia. Hipóteses, como a conexão causal entre um abuso sexual infantil e a fixação homossexual, a eficácia da influência e da sugestão do terapeuta sobre o paciente, dentro outras, servem de arma para tentativas de captura da legitimidade técnica das psicoterapias, da psicanálise e das ciências psicológicas como um todo. Talvez isso se dê porque nossas disciplinas psi vêm sofrendo de um discurso da eficácia que lhes acaba outorgando um direito a tentar mudar o outro em prol de uma demanda social qualquer. Como diria Tobie Nathan, um dos expoentes da etnopsiquiatria francesa, torturar é acima de tudo modificar o outro (Maleval, 2012).

Diante disso, precisamos depurar os pontos cegos, que chamados aqui de fósseis éticos, técnicos e teóricos, com vistas a não amealharmos em nossas práxis toda uma série de demandas e, até mesmo, de princípios de direção de tratamento que oriundos de curas morais, de curas religiosas e desses resíduos do religioso que encharcam todo nosso tecido social. No caso das terapias de conversão de gênero, um dos grandes riscos é que o grande público não enxergue que há diferenças de sentido (Binkowski, 2012) e de ética entre as proposições advindas de nossas práticas daquelas manipuladas por grupos religiosos.

\section{Referências}

Binkowski, G. (2012). Quand le religieux néopentecostiste s'approche des politiques du psychique, ou un cas d'intervention sur la régulation des pratiques psy au Brésil: De la gestion des âmes à la maîtrise du corps, des législations et des techniques. In J. García-Ruiz (Org.), Le religieux, lieux du politique em Amérique Latine. Paris: École des Hautes Études em Sciences Sociales. 
Breuer, J., \& Freud, S. (1971). Études sur l'hystérie. Paris: PUF. (Obra original publicada em 1895).

Butler, J. (2005). Regulaciones de gênero. Laventana, 3(23), 7-36.

Charcot, J. -M. (2015). La foi qui guérit. Paris: Rivages. (Obra original publicada em 1892).

Coulmont, B. (2010). Sexualité. In R. Azria, \& D. Hervieu-Léger, Dictionnaire des faits religieux (pp. 1158-1161). Paris: PUF. Fath, S. (2005). Du ghetto au réseau: Le protestantisme évangélique em France 1800-2005. Genève: Labor et Fides.

Freud, S. (2011). L'avenir d'une illusion. Paris: Points. (Obra original publicada em 1927).

Lacan, J. (1998). Le séminaire livre V, les formations de l'insconscient. Paris: Le Seuil.

Lieberman, J. (2016). Psiquiatria: Uma história não contada. São Paulo, SP: Martins Fontes.

Maleval, J. C. (2012). Étonnantes mystifications: De la psychothérapie autoritaire. Paris: Navarin.

Menahem, R. (2003). Désorientations sexuelles: Freud et l'hommosexualité. Revue Française de Psychanalyse, (1), 11-25.

Natividade, M. (2006). Homossexualidade, gênero e cura em perspectivas pastorais evangélicas. Revista Brasileira de Ciências Sociais, 21(61), 115-132. https://doi.org/10.1590/S0102-69092006000200006

Plunkett, P. (2009). Les évangéliques à la conquête du monde. Paris: Perrin.

Roudinesco, E. (2004). O paciente, o terapeuta e o estado. Rio de Janeiro, RJ: Jorge Zahar.

Roudinesco, E., \& Plon, M. (1998). Homossexualidade. In E. Roudinesco (Org.), Dicionário de psicanálise (pp. 350-355). Rio de Janeiro, RJ: Jorge Zahar.

Weber, M. (1964). L'éthique protestante et l'esprit du capitalisme. Paris: Plon. (Obra original publicada em 1905).

\section{Gabriel Binkowski}

Psicanalista. Mestre e Doutor em Psicologia pela Université Paris 13 Sorbonne, Paris. França. Pós-doutorando no Programa de Psicologia Clínica da Universidade de São Paulo (USP), São Paulo - SP. Brasil.

E-mail: gabriel.binkowski@gmail.com

(iD https:// orcid.org/0000-0003-4908-9221

Endereço para envio de correspondência:

Rua Caiubi, 553 - Perdizes - São Paulo - SP - 05010-000

Recebido 10/09/2019

Aceito 04/10/2019

Received 09/10/2019

Approved 10/04/2019

Recibido 10/09/2019

Aceptado 04/10/2019

Como citar: Binkowski, G. (2019). Fósseis do campo psi: sobre conversão de orientação sexual e gênero.

Psicologia: Ciência e Profissão, 39 (nspe.3), 236-241. https://doi.org/10.1590/1982-3703003228542

How to cite: Binkowski, G. (2019). Psy fossils: on sexual orientation conversion and gender. Psicologia: Ciência e Profissão, 39 (nspe.3), 236-241. https://doi.org/10.1590/1982-3703003228542

Cómo citar: Binkowski, G. (2019). Fósiles del campo psi: sobre conversión de la orientación sexual y del género. Psicologia: Ciência e Profissão, 39 (nspe.3), 236-241. https://doi.org/10.1590/1982-3703003228542 